\title{
PENGABDIAN KKN-MANDIRI TEMATIK KELURAHAN ONEKORE KABUPATEN ENDE
}

\author{
Yulita Londa ${ }^{*}$, Yulita Tanda ${ }^{2}$, Yohanes F Senda ${ }^{3}$, Yanuaris B Gabe ${ }^{4}$, Sirilus Sandy \\ Banda $^{5}$, Kristian E Turu More ${ }^{6}$, Hedwig Hendra Tegu Rani ${ }^{7}$ \\ 1,2,3,4,5,6,7 Universitas Flores, Indonesia \\ *Penulis Koresponsensi, email: selolitalonda@yahoo.com
}

\begin{abstract}
The general theme of the 2020 Community Service Program is "Community Empowerment". Meanwhile, the special theme is "Entrepreneurship". The implementation time starts from August 3 to September 3, 2020, in Onekore Village, Ende Tengah District, Ende Regency. On the program. With this special theme, the main activity carried out is supporting entrepreneurship in Onekore Village. The purpose of implementing this activity is that students are expected to gain learning experience through direct involvement in the community in finding, formulating, solving, and overcoming problems in the field. In this KKN activity, the problems found were the lack of utilization of existing garden products, namely bananas. So far, it is consumed by boiling or eating it without further processing. Also besides, we also found woven products from weaving that were difficult to market. Students socialize and practice entrepreneurship as an effort to solve problems faced by weaving craftsmen. Efforts made to help the household economy include making flower pots and making wallets made from woven fabrics. Supporting activities during the Community Service Program are assisting with the administration of the Village, community service, building a gate for the Indonesian Independence Day, making sample gardens, socializing COVID-19 and, health service for the elderly.
\end{abstract}

Keywords: Socialization, Chocolate Banana, Flower Pot, Woven Wallet

\begin{abstract}
Abstrak. Tema umum KKN tahun 2020 adalah "Pemberdayaan Masyarakat". Sedangkan tema khususnya adalah "Kewirausahaan". Waktu pelaksanaannya mulai dari tanggal 03 Agustus sampai dengan tanggal 03 September tahun 2020 di Kelurahan Onekore Kecamatan Ende Tengah Kaupaten Ende. Pada program. Dengan tema khusus ini, kegiatan utama yang dilakukan adalah mendukung kewirausahaan di kelurahan Onekore. Tujuan dari pelaksanaan kegiatan ini mahasiswa diharapkan memperoleh pengalaman belajar melalui keterlibatan dalam masyarakat secara langsung menemukan, merumuskan, memecahkan dan menanggulangi permasalahan yang berada dilapangan. Pada kegiatan KKN ini masalah yang ditemukan kurangnya pemanfaatan hasil kebun yang ada yaitu pisang. Selama ini dikonsumsi dengan cara direbus atau dimakan tanpa diolah lebih lanjut. Selain itu ditemukan juga hasil tenunan dari pengrajin tenun ikat yang sulit dipasarkan. Mahasiswa melakukan sosialisasi dan praktek kewirausahaan sebagi upaya pemecahan masalah yang dihadapi oleh pengrajin tenun ikat. Usahausaha yang dilakukan dalam upaya membantu ekonomi rumah tangga adalah pembuatan pot bunga, dan pembuatan dompet berbahan dasar tenun ikat. Kegiatan pendukung selama masa KKN adalah membantu pelaksanaan administrasi Kelurahan, kerja bakti, pembuatan gapura HUT RI, pembuatan kebun contoh, sosialisasi COVID-19 dan, posyandu lansia.
\end{abstract}

Kata Kunci: Sosialisasi, Pisang Coklat, Pot Bunga, Dompet Tenun.

How to Cite: Londa, Y., Tanda, Y., Senda, Y. F., Gabe, Y. B., Banda, S. S., More, K. E. T., \& Rani, H. H. T. (2021). PENGABDIAN KKNMANDIRI TEMATIK KELURAHAN ONEKORE KABUPATEN ENDE. Mitra Mahajana: Jurnal Pengabdian Masyarakat, 2(1), 97-104. https://doi.org/10.37478/mahajana.v2i1.785

\section{PENDAHULUAN}

Kelurahan Onekore merupakan salah satu kelurahan yang berada dalam kota Ende, tepatnya di kecamatan Ende Tengah, Kabupaten Ende. Batas wilayah Onekore sebelah barat berbatasan dengan Kelurahan Kota Raja, sebelah timur berbatasan dengan Kelurahan Pu'upira, utara berbatasan dengan hutan lindung Nuabosi dan sebelah selatan berbatasan dengan kelurahan Potulando. Pembagian wilayah administrasi kelurahan terdiri dari 5 Lingkungan yaitu Lingkungan Onekore, Potunggo, Nuawawo, Nuamuri dan Diponegoro. Luas wilayah Kelurahan Onekore 310,18 Ha yang terdiri dari tanah pemukiman 158,18 Ha, tanah subur 113 Ha dan tanah kritis 46 ha. Jumlah penduduk berdasarkan Kepala Keluarga (KK) adalah 
berjumlah $1.351 \mathrm{KK}$, sedangkan berdasarkan jumlah jiwa, penduduk Kelurahan Onekore berjumlah 9.234 jiwa yang terdiri dari 3.712 orang laki-laki dan 5.522 orang perempuan.

Penduduk Kelurahan Onekore umumnya bergerak dibidang bertani dan usaha dagang. Berikut ini rincian data penduduk menurut kelompok mata pencaharian dan pendidikan. Data penduduk menurut mata pencaharian: petani 1.024 orang, nelayan 13 orang, kerajinan 275 orang, usaha dagang 517 orang, PNS 757 orang, TNI/Polri 16 orang, swasta 513 orang, buruh 425 orang, pensiunan 352 orang, mengurus rumah tangga 1.438 orang dan lainnya 3.913 orang. Data penduduk menurut pendidikan: SD 2.276 orang, SLTP 1.761 orang, SLTA 1.825 orang, Diploma 392 orang, Strata I 451 orang, Strata II 62 orang, lainnya 2.467 orang.

Pada kegiatan Pengabdian KKN Mandiri ini, mahasiswa mengambil tema kewirausahaan. Dari tema ini mahasiswa memberikan motivasi dan sosialisasi tentang kewirausahaan. Tujuan pelaksanaan program ini agar mahasiswa memperoleh pengalaman belajar melalui keterlibatan dalam masyarakat secara langsung untuk menemukan, merumuskan, memecahkan dan menanggulangi permasalahan dalam kehidupan bermasyarakat. Pada kegiatan KKN ini masalah yang ditemukan antara lain kurangnya pemanfaatan hasil kebun yang ada yaitu pisang. Selain itu ditemukan juga hasil tenunan dari pengrajin tenun ikat yang sulit dipasarkan.

Dalam prinsipnya, KKN bermakna untuk menerapkan Ilmu pengetahuan dan teknologi telah diperoleh mahasiswa selama mengikuti kuliah di Kampus. Agar pengetahuan dapat bermanfaat maka pengetahuan itu harus diterapkan di tengah masyarakat. Ilmu pengetahuan yang dimiliki secara moral harus ditujukan untuk kebaikan manusia tanpa merendahkan martabat atau mengubah hakikat manusia (Dhedhi Irwanto, 2017). Dengan bekal ilmu pengetahuan yang diperoleh dan kemampuan teknologi yang dimiliki mahasiswa diharapkan dapat mencari solusi dalam menanggulangi masalah yang dihadapi oleh masyarakat sasaran.

\section{METODE PELAKSANAAN}

Kuliah Kerja Nyata (KKN) tematik integratif dengan tema umum "Pemberdayaan Masyarakat" dan tema khusus "Kewirausahaan" (Anwas, 2011) (Wolo, Ngapa \& Harlyanti, 2020). Waktu pelaksanaannya mulai dari tanggal 3 Agustus sampai dengan tanggal 3 September tahun 2020 di Kelurahan Onekore, Kecamatan Ende Tengah, Kaupaten Ende. Pelaksanaan KKN dibagi dalam beberapa tahapan kegiatan. Kegiatan pertama yakni pengumpulan data. Pengumpulan data dilakukan dengan obserpoti di lokasi KKN guna mendapatkan gambaran umum tentang lokasi dan kondisi masyarakat supaya dapat menyusun program kerja selama periode pelaksanaan KKN. Selain itu, diskusi bersama para staf kepegawaian di kelurahan setempat dilakukan guna umengetahui data-data yang berhubungan dengan Monografi Kelurahan. Data yang diperoleh dalam pengumpulan data akan diolah menggunakan statistik deskriptif. Hasil olahan akan disajikan dalam bentuk tabel dan grafik. Hasil olahan data dapat digunakan untuk penyusunan program kegiatan dalam menyelesaikan atau memecahkan masalah yang dihadapi masyarakat Kelurahan Onekore.

Program kegiatan kemudian disusun berdasarkan hasil analisis data akan diselesaikan selama masa KKN. Solusi yang ditawarkan dalam pemecahan masalah yang dihadapi masyarakat Kelurahan Onekore yang sudah teridentifikasi adalah melakukan sosialisasi yang berkaitan dengan kegiatan kewirausahaan yaitu penggunaan HP dikalangan pengrajin tenun ikat sebagai media promosi online (market palace di Face Book). Lebih lanjut, praktek kewirausahaan yaitu latihan pembuatan pisang coklat, pembuatan pot bunga, pembuatan dompet berbahan dasar tenun ikat juga dilakukan sebagai program kegiatan KKN ini. Bahan yang digunakan adalah pisang, coklat, semen, kain tenun ikat. Dalam program ini, dilaksanakan pula kegiatan pendukung lainya yakni membantu pelaksanaan administrasi Kelurahan, kerja bakti, pembuatan gapura hari ulang tahun kemerdekaan NKRI, pembuatan kebun contoh, penyuluhan New Normal yang berkaitan dengan COVID-19 serta posyandu lansia.

\section{HASIL DAN PEMBAHASAN}

Kegiatan KKN dilaksanakan oleh mahasiswa bersama dosen pembimbing lapangan (DPL) di Kelurahan Onekore Kabupaten Ende mulai hari Senin tanggal 3 Agustus sampai dengan hari 
Yulita Londa, Yulita Tanda, Yohanes F Senda, Yanuaris B Gabe, Sirilus Sandy Banda, Kristian E Turu More, Hedwig Hendra Tegu Rani

Mitra Mahajana: Jurnal Pengabdian Masyarakat 2(1), 2021, 97-104

Kamis 3 September 2020 (Wolo, Ngapa \& Harlyanti, 2020). Hari pertama mahasiswa peserta KKN menuju ke lokasi KKN untuk melapor dan memperkenalkan diri kepada pimpinan wilayah setempat dalam hal ini Lurah Onekore. Selanjutnya mahasiswa peserta KKN mulai melakukan setiap tahapan KKN yang sudah direncanakan. Setiap minggu, mahasiswa melaporkan hasil kegiatan selama satu minggu kepada DPL yang selanjutnya DPL melaporkan kepada Panitia. Laporan dikirim secara online kedalam aplikasi e-learning, sehingga mahasiswa tidak mengalami kesulitan walaupun KKN dilaksanakan dimasa pandemik COVID-19. Format laporan sudah disiapkan oleh Panitia. Bentuk Laporan berupa narasi, dokumentasi foto dan video. DPL membaca setiap laporan mingguan mahasiswa dan memberikan solusi jika ada kendala dalam pelaksanaan kegiatan.

Salah satu kegiatan yang dilaksanakan yakni sosialisasi tentang bagaimana cara menggunakan Hand Phone (HP) atau memaksimalkan fungsi HP untuk mempromosikan penjualan tenun ikat hasil usaha dari pengrajin tenun. Sebagai media promosi online (market palace di Facebook), diharapkan dapat membantu mengatasi masalah penjualan yang tersendat selama ini (Ismanto, dkk., 2020) (Mamulak, 2020). Sosialisasi dilakukan dihadapan ibu-ibu pengrajin tenun ikat di Kelurahan Onekore.
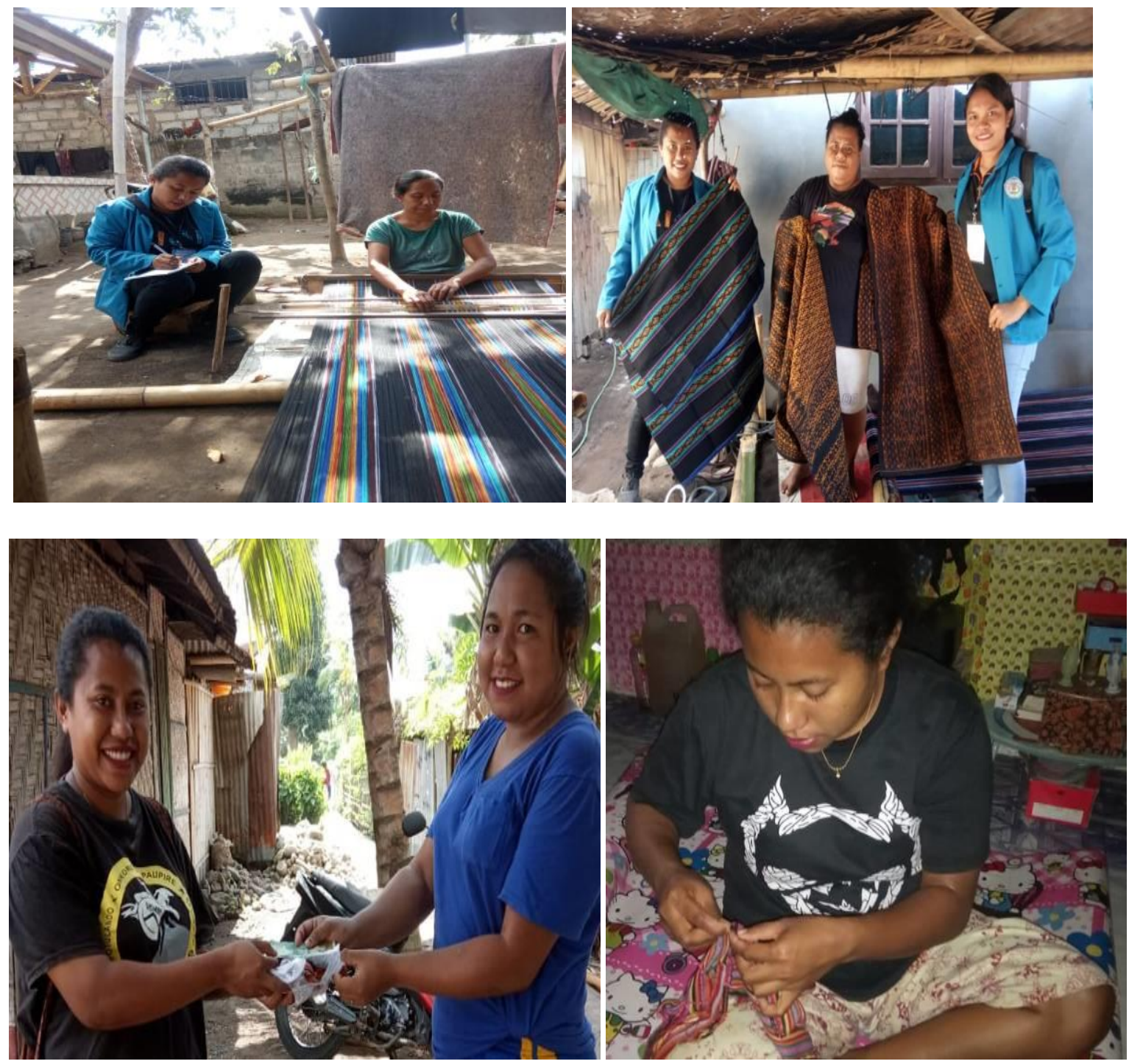

Gambar 1. Mahasiswa bersama para penenun tenun ikat 
Saat ini, pemanfaatan media sosial seperti facebook, twitter dan instagram banyak digunakan sebagai media promosi produk. Tentunya cara ini akan sangat efektif, karena bentuk pemasaran online tidak hanya dijangkau oleh masyarakat local, namun juga dari seluruh penjuru dunia (Doni Irvan, 2016). Salah satu pasar online yang langsung disosialisasikan dan diaplikasikan ilaha menggunaan jasa market place yang disediakan oleh Facebook. Para Facebooker dapat mengenal produk-produk yang dihasilkan oleh para pengrajin termasuk pengrajin tenun ikat di Kelurahan Onekore. Para pengrajin dapat langsung mempromosikan hasil tenun ikatnya dalam Market Palace (Nurfarida \& Adi P, 2016) (Budiman, dkk 2020). Kegiatan ini tentu mendapat respon yang cukup positif dari para pengrajin tenun ikat setempat. Selain kreatif, hal yang dirasakan oleh para pengrajin ialah inovatif. Dengan inovasi penjualan media online, wirausahawan menciptakan baik sumber daya produksi baru maupun pengelolahan sumber daya yang ada dengan peningkatan nilai potensi untuk pemasaran yang lebih luas jangkauannya.

Lebih lanjut, kegiatan yang dilakukan dalam program ini ialah praktek kewirausahaan (Alfianto, 2012) (Ajmal As'ad, Syahnur \& Arumbarkah, 2019). Latihan pembuatan pisang coklat tabur keju menjadi salah satu kegiatan yang bertujuan menambah pengetahuan dan menumbuh minat berwirausaha serta meningkatakan kreativitas ibu-ibu rumah tangga dalam membantu ekonomi keluarga (Hapsari, Maulita \& Umdiana, 2019).. Kegiatan ini dilaksanakan diaula kelurahan onekore 4 Agustus 2020. Hambatan yang dialami kurangnya waktu dan bahan yang tersedia. Masyarakat yang berpartisipasi adalah ibu-ibu rumah tangga yang dekat pada wilayah kantor lurah dan mahasiswa KKN (langkah ini diambil guna meminimalisisr kerumunan dan mematuhi protocol kesehatan). Program ini berjalan dengan lancar.
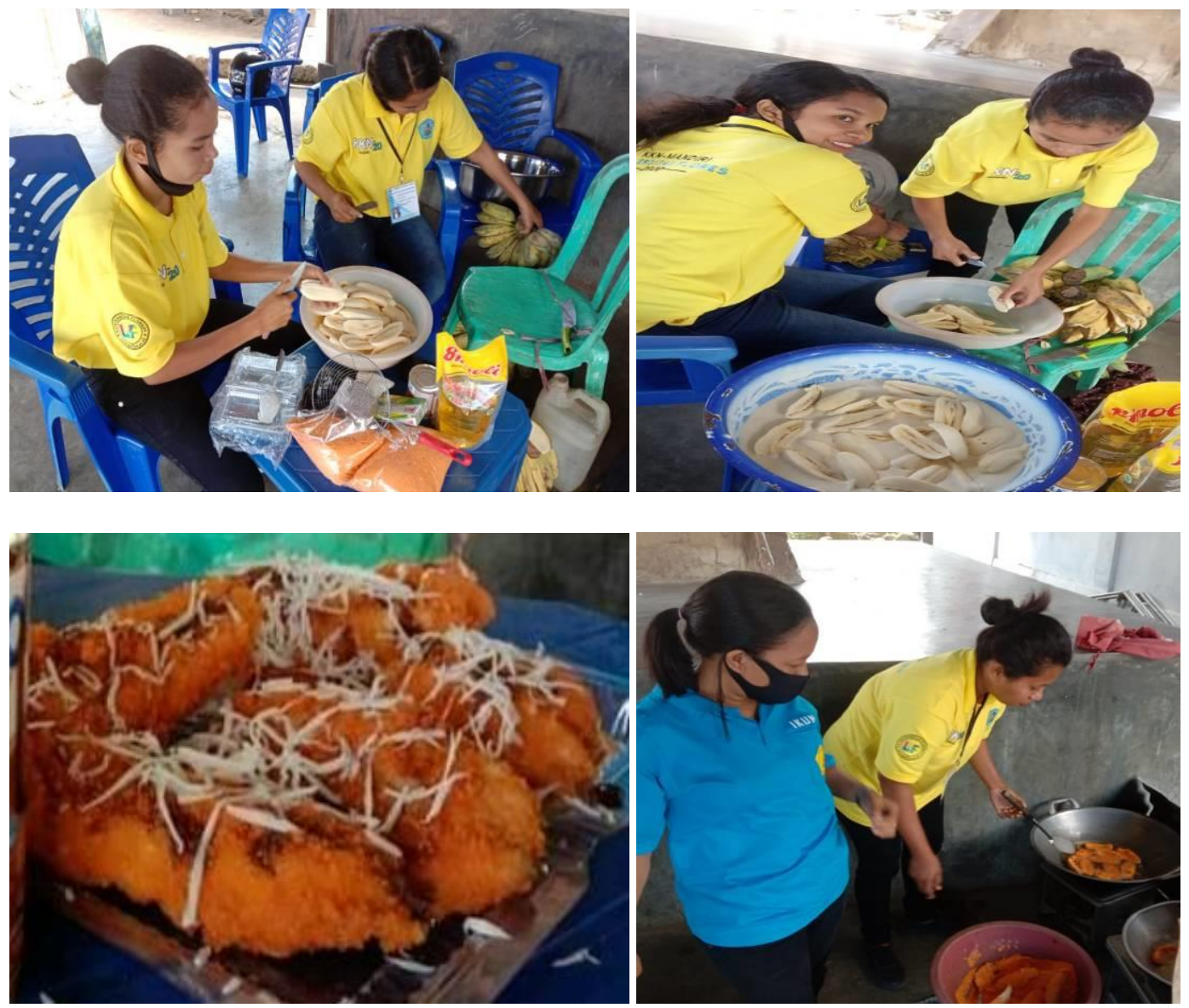

Gambar 2. Praktek Pembuatan Pisang Coklat Tabur Keju. 
Program kewirausahaan lainnya ialah latihan pembuatan pot bunga. Program ini bertujuan untuk menambah wawasan dan pengetahuan bagi warga, juga dapat mengurangi pengeluaran kas untuk membeli pot bunga. Dengan adanya pengetahuan pembuatan pot bunga, masyarakat dapat membuat sendiri pot untuk keperluan sendiri dan dijual kepada masyarkat untuk menambah penghasilan (Hartini, Alang \& Apriyanti, 2021). Tidak ada kendala, kegiatan berjalan baik. Pihak yang terlibat diutamakan ialah para usia produktif diutamakan anak muda. Program dilaksanakan pada tanggal 26 agustus2020. Bahan yang dibutuhkan diutamakan menggunakan bahan bekas sebagai bentuk kepedulian akan daurulang sampah menjadi bahan berguna (Masyono, 2013
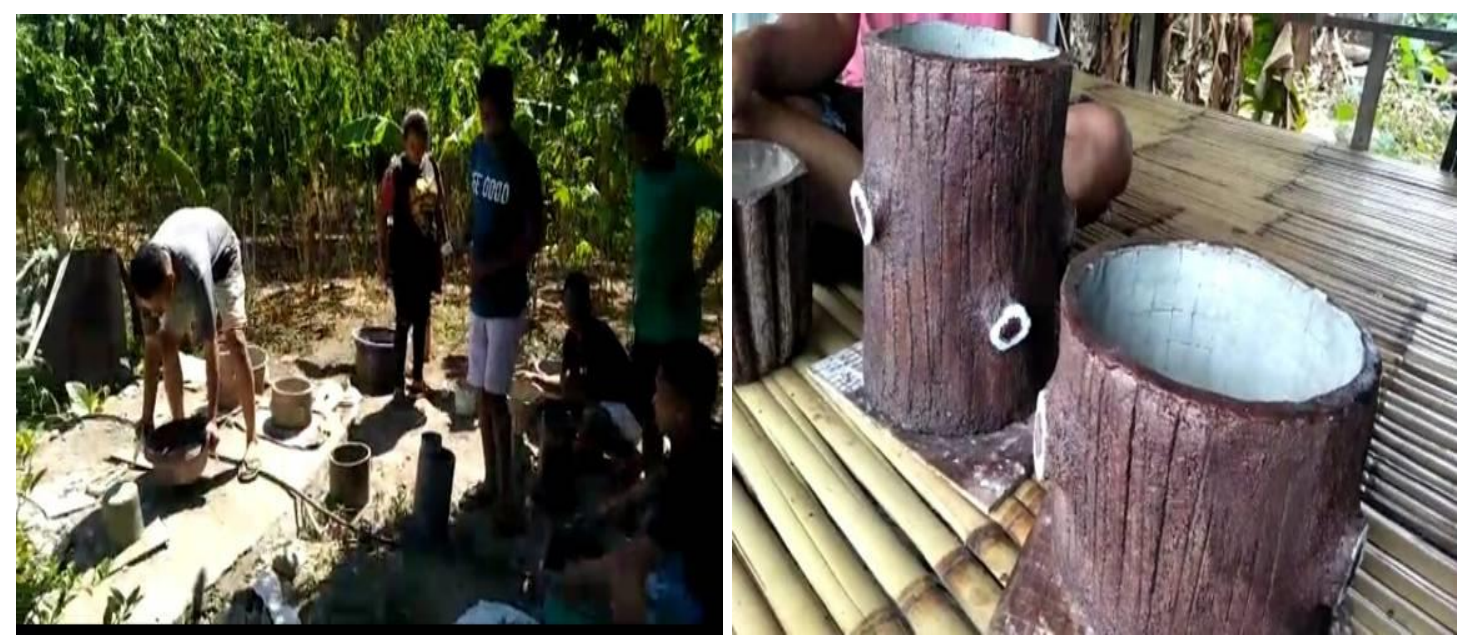

Gambar 3. Praktek Pembuatan Pot Bunga dari Semen

Lebih lanjut, kegiatan pendukung lainnya selama masa KKN selain kegiatan yang bersifat tematik, mahasiswa juga melakukan kegiatan Kegiatan tematik pertama ialah membantu pelaksanaan admistrasi Kelurahan (Asmanang, dkk. 2020). Mahasiswa peserta KKN membantu admistrasi kelurahan dalam membuat surat keterangan usaha, surat keterangan tidak mampu, perpindahan penduduk, surat berpergian (dinas), surat belum dan sudah kawin;
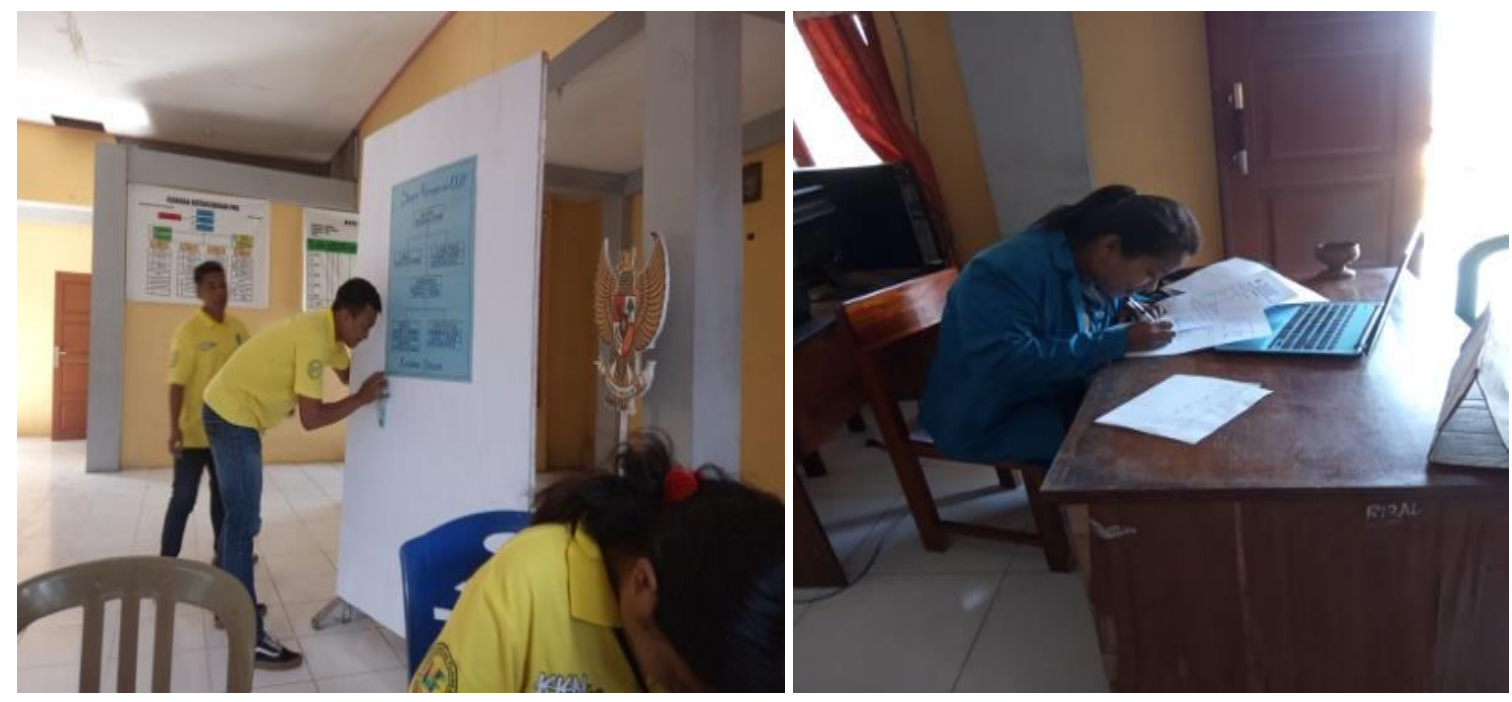

Gambar 4. Membantu administrasi Kelurahan Onekore 
Kegiatan tematik kedua yang dilakukan ialah kerjabakti bersama. Dalam rangka menjaga kebersihan lingkungan sekitar, salah satu upaya yang bisa dilakukan warga adalah peduli dengan lingkungan sekitar, membuang sampah pada tempatnya dan ikut serta membersihkan lingkungan," urainya. Kegiatan ini dilaksanakan oleh mahasiswa dan staff pemerintahan kelurahan onekore. Kegiatannya berupa gotong-royong di sepanjang jalan Nuamuri dan pangkalan trevel Ndao.
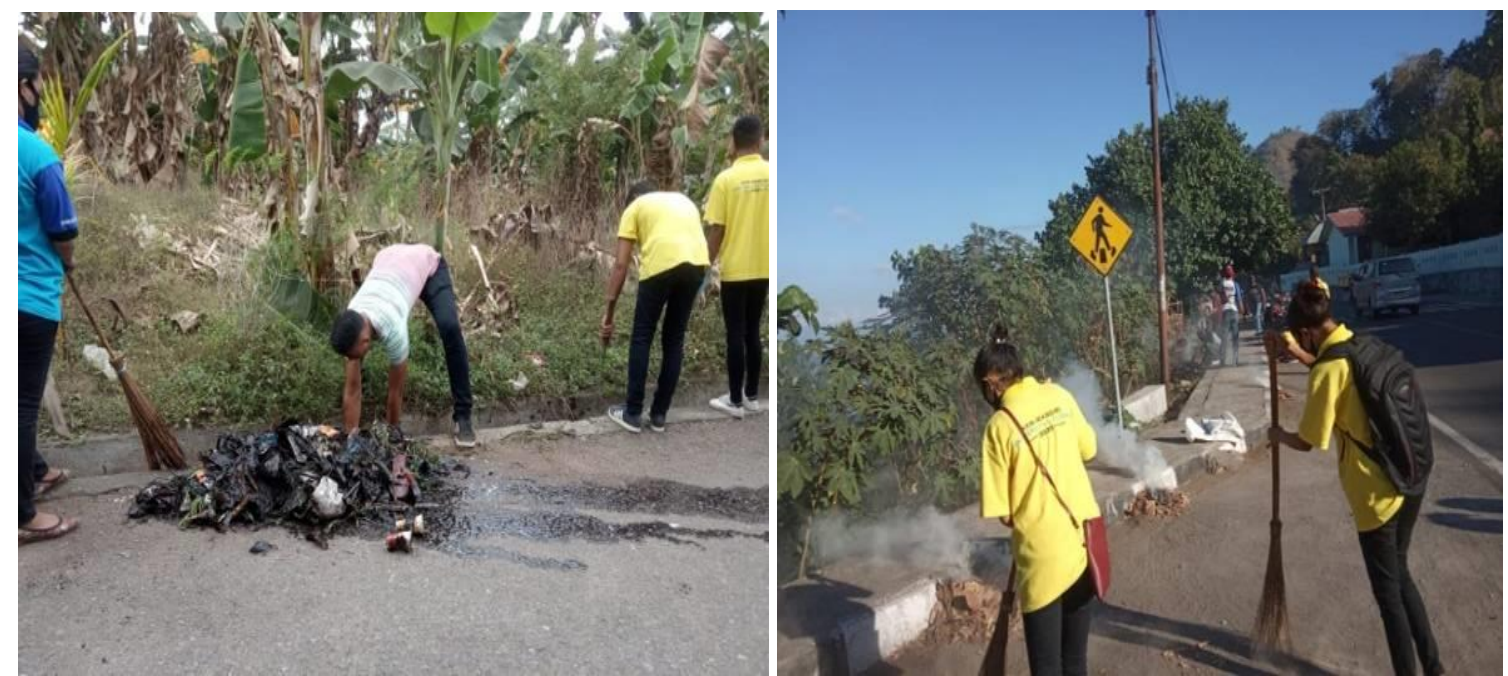

Gambar 5. Kerja Bakti

Kegiatan tematik berikutnya ialah pembuatan kebun contoh. Kegiatan ini merupakan recana ibu PKK dan kelurahan onekore dan dibantu oleh mahasiswa KKN pada tanggal 19 Agutus 2020. Pihak yang terlibat adalah ibu PKK, Lurah onekore dan stafnya, Dinas Pertanian dan mahasiswa KKN. Semua kegiatan pendukung dapat terlaksana dengan baik dan lancar.

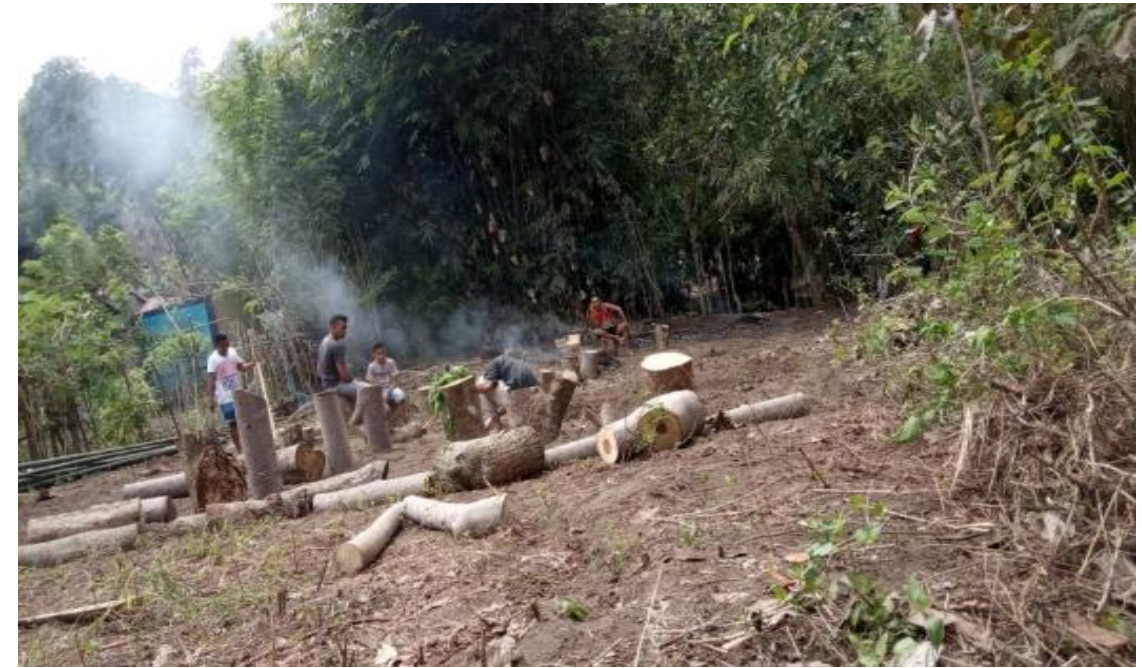

Gambar 6. Pengolahan Kebun Contoh

Lebih lanjut kegiatan tematik lainnya ialah penyuluhan new normal sosial. Kegiatan ini dilaksanakan pada 18 Agustus 2020. Maksud dan tujuan dilaksanakan kegiatan ini adalah untuk meningkatkan kesadaran publik dan perubahan perilaku masyarakat adaptasi kebiasaan baru dan masyarakat sadar menggunakan masker, mencuci tangan dengan sabun diair mengalir dan jaga jarak /hindari kerumunan. Kendala yang ditemukan ada sebagaian masyarakat yang tidak menggunakan masker. Solusi yang diberikan mengadakan pembagian masker, pihak kesehatan melakukan penyuluhan bagaimana mencuci tangan yang benar, jaga jarak, harus memakai 
masker. Lurah Onekore dan pihak keamanan memberi penegasan dan kesadaran kepada masyarakat. Pihak-pihak yang terlibat dalam kegiatan ini adalah warga, Lurah Onekore, pihak keamanan, kepala puskesmas Onekore, para tenaga kesehatan setempat dan mahasiswa KKN.
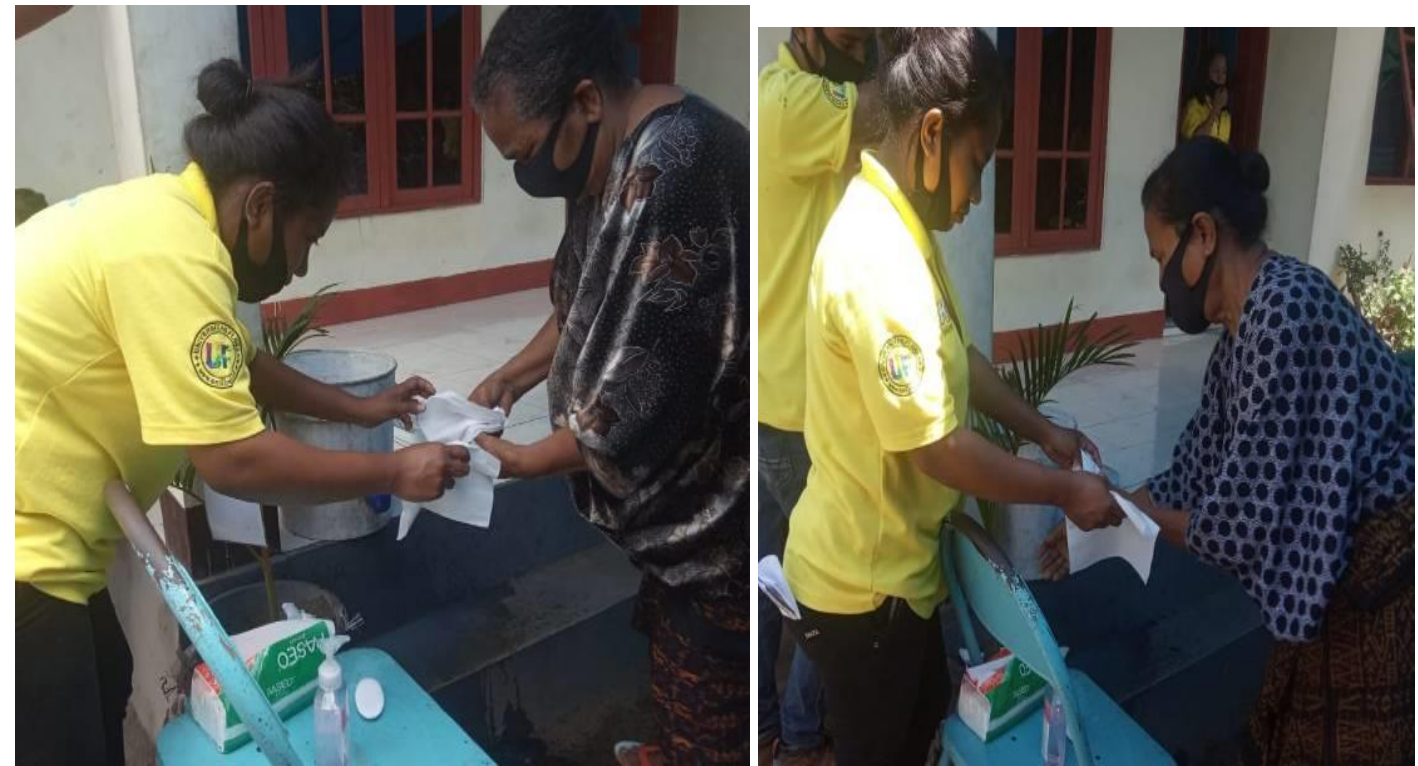

Gambar 7. Penyuluhan New Normal COVID-19. Cuci Tangan, Pakai Masker, Jaga Jarak

Kegiatan tematik terakhir ialah Posyandu Lansia. Posyandu lansia menurut UU No. 13 tahun 1998 merupakan wadah pelayanan kepada lansia di masyarakat yang menitikberatkan pelayanan kesehatan, psikologis, rohani, pemenuhan gizi agar lansia dapat memenuhi kebutuhannya dan kesejahteraan sosial yang memadai. Mahasiswa KKN membantu pihak kesehatan dalam mendampingi pemeriksaan lansia yang dilaksanakan pada 14 Agustus 2020 tanggal. Tidak ada kendala yang ditemukan, semuanya berjalan lancar, pihak yang terlibat warga Nuamuri, para tenaga kesehatan setempat (bidan) dan mahasiswa KKN.
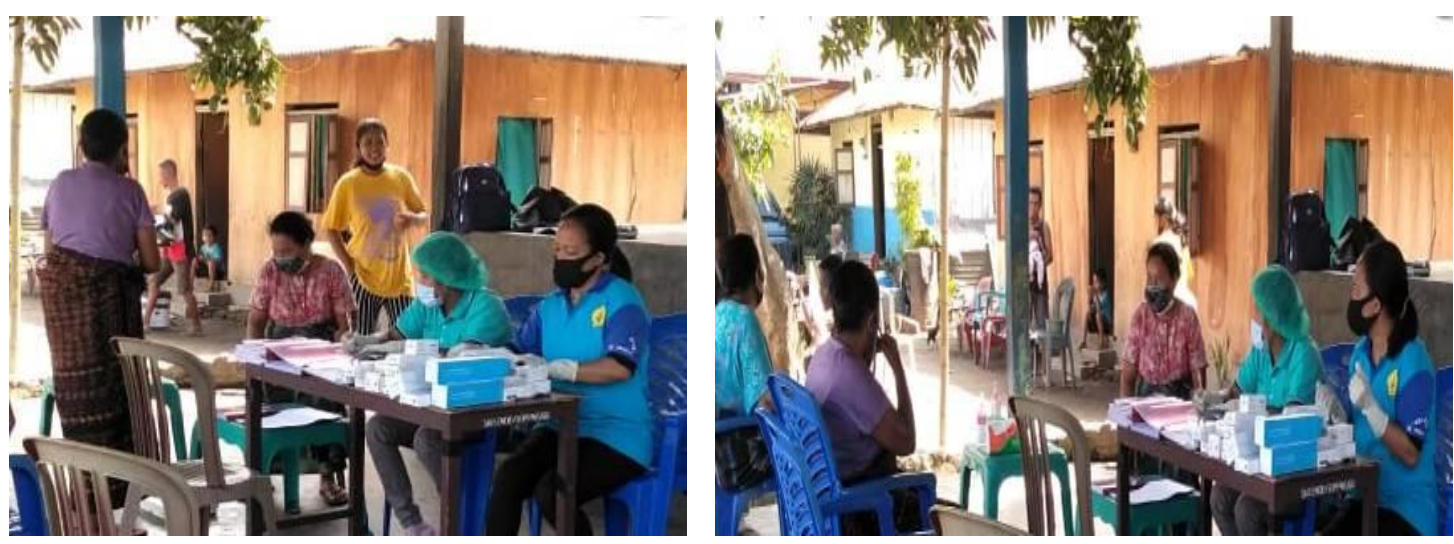

Gambar 9. Posyandu Lansia

\section{SIMPULAN DAN TINDAK LANJUT}

Berdasarkan pelaksanaan kulia kerja nyata (KKN) Universitas Flores 2020 di Kelurahan Onekore, kecamatan Ende Tengah, Kabupaten Ende dapat disimpilkan bahwa semua kegiatan berjalan baik dengan lancar. Program yang dilaksanakan merupakan program kewirausahaan dan program Kelurahan Onekore. Partisipasi masyarakat cukup tinggi, dimana masyarakat cukup aktif dalam pelaksanaan program sehinggamasyarakat dapat mengambil manfaatnya 
dengan lebih maksimal. Walaupun program KKN berjalan secara lancar, namun ada beberapa kendala dan hambatan dalam pelaksanaan program, seperti susahnya mengumpulkan masyarakat pada saat penyuluhan, dan persiapan yang kurang ketika program dilaksanakan.Berbagai program kegiatan yang sudah dijalankan dalam KKN ini, semoga dapat memberi banyak manfaat bagi mahasiswa KKN dan masyarakat Kelurahan Onekore terutama dalam mendukung pembangunan kelurahan. Adapun saran atau tindak lanjut untuk kegiatan KKN ialah waktu kegiatan ditambah agar mahasiswa memiliki waktu yang cukup dalam menjalankan program kegiatannya.

\section{DAFTAR PUSTAKA}

Alfianto, E. A. (2012). Kewirausahaan : Sebuah Kajian Pengabdian Kepada Masyarakat. Jurnal Heritage. 1(2), 33-42

Anwas, O. M. (2011). Kuliah Kerja Nyata Tematik Pos Pemberdayaan Keluarga Sebagai Model Pengabdian Masyarakat Di Perguruan Tinggi. Jurnal Pendidikan dan Kebudayaan, 17(5), 565-575

As'ad, A., Syahnur, H \& Arumbarkah, M. (2019). Pelatihan Motivasi dan Kewirausahaan Bagi Warga Desa. Jurnal Pengabdian Bina Ukhuwah. 1(2)

Asmanang, L., Herman, H., Tawakal, F., Indra, I., Puadji, F., Setianingsi, E., Sa’ban, L., \& Hastuti, H. (2020). PEMBINAAN ADMINISTRASI DESA DI DESA WAJAJAYA. INTEGRITAS : Jurnal Pengabdian, 4(1), 87 - 94. doi:10.36841/integritas.v4i1.518

Budiman, D. F., Rahman, A. S., Iqbal, M. S., Misbahuddin, M., \& Wiriasto, G. W. (2020). Pelatihan Internet Market Place Bagi Pengrajin Tenun Songket Desa Sukerare Kecamatan Jonggat Lombok Tengah. Jurnal PEPADU, 1(1), 81-84.

Dhedhi Irawanto. (2017). Kedudukan Ilmu Dalam Kehidupan Manusia. Pada:https://hminews.com/2017/05/opini/kedudukan-ilmu-dalam-kehidupan-manusia/

Doni Irvan. (2016). 6 Peran Teknlogi Dalam Bisnis Anda Menjadi Sukses. Pada:https://accuratecloud.id/2016/12/09/6-peran-teknologi-dalam-bisnis/

Hapsari, D. P., Maulita, D., \& Umdiana, N. (2019). Peningkatan Ekonomi Rumah Tangga Dengan Pengolahan Pisang. KAIBON ABHINAYA: JURNAL PENGABDIAN MASYARAKAT, 1(2), 78-83.

Alang, H., \& Apriyanti, E. (2021). PELATIHAN PEMBUATAN POT BUNGA DENGAN BAHAN DASAR KAIN BEKAS DI DESA KINDANG. RESWARA: Jurnal Pengabdian Kepada Masyarakat, 123-130.

Ismanto, H., Tamrin, M. H., \& Edward, M. Y. (2020). Pendampingan UKM Tenun Ikat Troso dalam Pengelolaan Model Pemasaran Berbasis Online. E-Dimas: Jurnal Pengabdian kepada Masyarakat, 11(1), 87-95.

Kemdikbud RI (2019). Kamus Besar Bahasa Indonesia Online, pada: https://kbbi.web.id/

Mamulak, N. M. R. (2020). Kesiapan UMKM Tenun Ikat dalam Pemanfaatan Inovasi Teknologi ECommerce di Kota Kupang. Jurnal Inovasi Kebijakan, 5(1), 1-11

Nurfarida, E., \& Adi P, A. K. (2016). Web Marketplace Guna Meningkatkan Daya Saing UMKM Kota Kediri. J-Dinamika: Jurnal Pengabdian Masyarakat, 1(2). https://doi.org/10.25047/idinamika.v1i2.186

Qurniati, R., Duryat, D., Prasetya, H., \& Hartati, F. (2020). Olahan Pisang sebagai Penunjang Ekonomi Masyarakat di Sekitar Gunung Rajabasa Lampung. J-ABDIPAMAS Uurnal Pengabdian Kepada Masyarakat), 4(2), 117-124

Undang-Undang Republik Indonesia Nomor 13 Tahun 1998 tentang Kesejahteraan Lanjut Usia.

Wolo, D., Ngapa, Y. S. D., \& Harıyanti, M. L. (2020). Pengabdıan KKN-Mandırı Desa Golo Wuas Kabupaten Manggaraı Tımur. Mitra Mahajana: Jurnal Pengabdian Masyarakat, 1(1), 24-31 